\title{
Transient Severe Respiratory Motion Artifacts After Application of Gadoxetate Disodium: What We Currently Know
}

\author{
Transiente schwere Atemartefakte nach Gabe von \\ Dinatriumgadoxetat: Was wir derzeit wissen
}

Authors

Lennart Well, Julius Matthias Weinrich, Gerhard Adam, Peter Bannas

\section{Affiliation}

Department of Diagnostic and Interventional Radiology and Nuclear Medicine, University Medical Center Hamburg-

Eppendorf, Hamburg, Germany

Key words

transient severe motion artifacts, gadoxetate disodium, risk factors, dynamic contrast-enhanced MRI

received 22.06.2017

accepted 11.09.2017

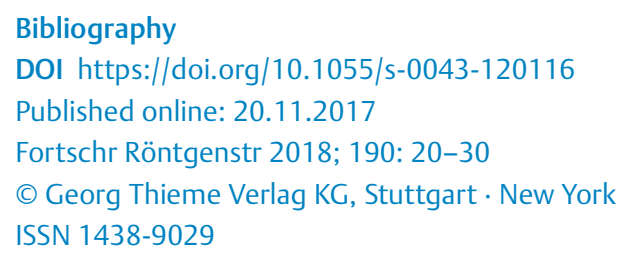

\section{ZUSAMMENFASSUNG}

Hintergrund Dinatriumgadoxetat ist ein intrazelluläres Kontrastmittel für die Leberbildgebung in der Magnetresonanztomografie (MRT). In aktuellen Publikationen wurde das Auftreten transienter schwerer Atemartefakte (TSA) nach Gabe von Dinatriumgadoxetat beschrieben, die zur Reduktion der Bildqualität in der arteriellen Konstrastmittelphase führen. In diesem Übersichtsartikel vergleichen wir den Einfluss publizierter Untersuchungsprotokolle und potentieller Risikofaktoren auf die Häufigkeit des Auftretens der TSA. Zudem diskutieren wir vorgeschlagene Strategien zur Vermeidung oder Minimierung der Effekte der TSA.

Methode Diese Übersichtsarbeit basiert auf einer Literaturrecherche der PubMed Datenbank, welche nach „transient severe motion artifact“ und verwandten Begriffen unabhängig voneinander von zwei Autoren durchsucht wurde. Die
Literaturverzeichnisse der identifizierten Arbeiten wurden ebenfalls durchsucht. Zwei Autoren wählten gemeinsam neun Arbeiten aus, in denen sowohl die Frequenz der TSA als auch potentielle Risikofaktoren untersucht wurden. Relevante Studiendaten wurden von den Autoren extrahiert, Diskrepanzen der extrahierten Daten wurden im Konsens gelöst.

Ergebnisse und Schlussfolgerungen Die TSA werden durch eine Beeinträchtigung der Atemanhaltefähigkeit nach Gabe von Dinatriumgadoxetat verursacht und treten in $5-22 \%$ aller Dinatriumgadoxetat-verstärkten Leber-MRTs auf. Die Kontrastmitteldosis, wiederholte Dinatriumgadoxetat-Exposition, hoher Body Mass Index sowie pulmonale Erkrankungen werden als potentielle Risikofaktoren für das Auftreten der TSA beschrieben. Allerdings finden sich nur wenig übereinstimmende Resultate hinsichtlich der Risikofaktoren, und die ursächliche Pathophysiologie der TSA ist bis heute ungeklärt. Vorgeschlagene Strategien zur Vermeidung der TSA sind niedrige Injektionsraten und Gabe von verdünntem, niedrig dosiertem Dinatriumgadoxetat. Durch kürzere Sequenzen, Aufnahmen ohne Atemstillstand und Atemtraining der Patienten soll der Effekt der TSA minimiert werden. Zukünftige prospektive Studien müssen diese Strategien bestätigen und den zugrundeliegenden Mechanismus für das Auftreten der TSA ermitteln.

\section{Kernaussagen}

- Die Dinatriumgadoxetat-verstärkte Leber-MRT führt in $5-22 \%$ zu transienten schweren Atemartefakten.

- Potentielle Risikofaktoren für TSA sind Kontrastmitteldosis, wiederholte Dinatriumgadoxetat-Gabe, BMI sowie Lungenerkrankungen.

- Die Ursache für das Auftreten von TSA ist bislang ungeklärt.

- Niedrige Injektionsraten und verdünntes Dinatriumgadoxetat sollen das Auftreten von TSA vermeiden.

- Kürzere oder durchgeatmete MRT-Sequenzen sollen den Effekt der TSA minimieren.

\section{ABSTRACT}

Background Gadoxetate disodium is an intracellular contrast agent for magnetic resonance imaging (MRI) of the liver. Recent publications revealed that injection of gadoxetate disodium can lead to imaging artifacts due to transient severe 
motion (TSM) in the arterial phase of contrast-enhanced liver MRI. In this review we present and discuss published frequencies of TSM, contrast injection and image acquisition protocols, potential risk factors, and proposed strategies to avoid or minimize the effects of TSM.

Method Two reviewers independently searched the PubMed search engine for "transient severe motion artifact" and related terms. Reference lists of retrieved articles were also searched. The two reviewers selected in consensus nine studies that reported both frequencies of TSM and potential risk factors. Study data were extracted by both reviewers, and disagreement was resolved by consensus.

Results and Conclusion TSM is caused by impaired breathhold ability after gadoxetate disodium injection and occurs in $5-22 \%$ of patients. The dose of applied contrast agent, repeated exposure to gadoxetate disodium, high BMI and pulmonary disease have been described as potential risk factors for TSM. However, there are only few concordant results on this topic and the pathophysiology of TSM has not been identified. Proposed strategies for the prevention of TSM are slow injection rates and low doses of diluted gadoxetate disodium. Accelerated and free-breathing MRI sequence protocols and breath-hold training may minimize the effects of TSM. Further prospective studies are needed to confirm these strategies and to identify the underlying mechanism of TSM.

\section{Key Points}

- TSM occurs in 5-22\% of patients after gadoxetate disodium injection.

- Potential risk factors of TSM are dose, repeated exposure, BMI, pulmonary disease.

- The underlying mechanism for TSM has not been identified.

- Slow injection rates and diluted gadoxetate disodium may prevent TSM.

- Accelerated image acquisition or free-breathing sequences may mitigate the effects of TSM.

\section{Citation Format}

- Well L, Weinrich JM, Adam G et al. Transient Severe Respiratory Motion Artifacts After Application of Gadoxetate Disodium: What We Currently Know. Fortschr Röntgenstr 2018; 190: 20-30

\section{Introduction}

Gadoxetate disodium (Primovist/Eovist; Bayer Healthcare, Wayne, $\mathrm{NJ}$ ) is a gadolinium-based contrast agent for magnetic resonance imaging (MRI) of the liver [1 -4]. It enables both dynamic contrast-enhanced T1-weighted imaging and hepatobiliary phase imaging within approximately 30 minutes [5].

Unfortunately, recent reports described the occurrence of artifacts in the arterial phase in clinical liver MRI after the injection of gadoxetate disodium [6]. This phenomenon was first described and named as such by Davenport et al. in 2013 who termed it "transient severe motion" (TSM) [6, 7]. It is defined as a sudden onset of severe motion-related artifacts due to breath-hold failure during the arterial contrast phase without any motion artifacts in the pre-contrast and delayed contrast phases ( $\triangleright$ Fig. $\mathbf{1}$ ).

The artifacts in the arterial phase of gadoxetate disodium-enhanced liver MRI caused by TSM may diminish the advantages of gadoxetate disodium hepatobiliary phase imaging.

In this review, we present and discuss frequencies of TSM, contrast injection and image acquisition protocols, potential risk factors und proposed strategies to avoid or minimize the effects of TSM in recent publications. We also offer a perspective on further necessary research regarding TSM.

\section{Materials and Methods}

The PubMed search engine (http://www.pubmed.gov) was searched for "transient severe motion," "motion artifact," and related terms in articles published since the first description of TSA in February 2013 and May 2017 (\$ Fig.2). Reference lists of retrieved articles were also searched. No language restrictions were applied. For direct comparison, two reviewers independently selected eligible primary studies, with disagreement resolved by consensus. The inclusion criteria for direct comparison were as follows: a) undiluted injection of contrast agent, b) analysis of frequencies of TSM, c) analysis of at least ten potential risk factors for TSA. Studies were excluded if any one of the inclusion criteria was not met.

The same two reviewers extracted the data from the full text of the selected primary studies. Extracted data included the provided frequencies of TSM, publication date, journal, and country of origin. Regarding patient characteristics, age and BMI were extracted. Furthermore, we extracted details of the injection protocols such as volume and concentration of contrast agent, injection rates, and volume of saline chasers. We further extracted sequence parameters of the MR acquisition protocols and results of assessments of potential risk factors for the appearance of TSM.

\section{Results and Discussion}

\section{Literature search}

The literature search identified 4336 articles possibly fulfilling the inclusion criteria ( $\triangleright$ Fig. 1). After the screening of titles and abstracts, 4254 articles were excluded because of non-TSA-related topics. The remaining 82 articles were evaluated by reading the full text. Of these, 62 articles were excluded because they did not focus on TSA and the underlying risk factors. The remaining 20 articles were included and are discussed in the review. Of these, eleven articles were excluded because they did not fulfill the inclusion criteria that would allow for a direct comparison. The remaining nine articles that reported on frequencies of TSA 

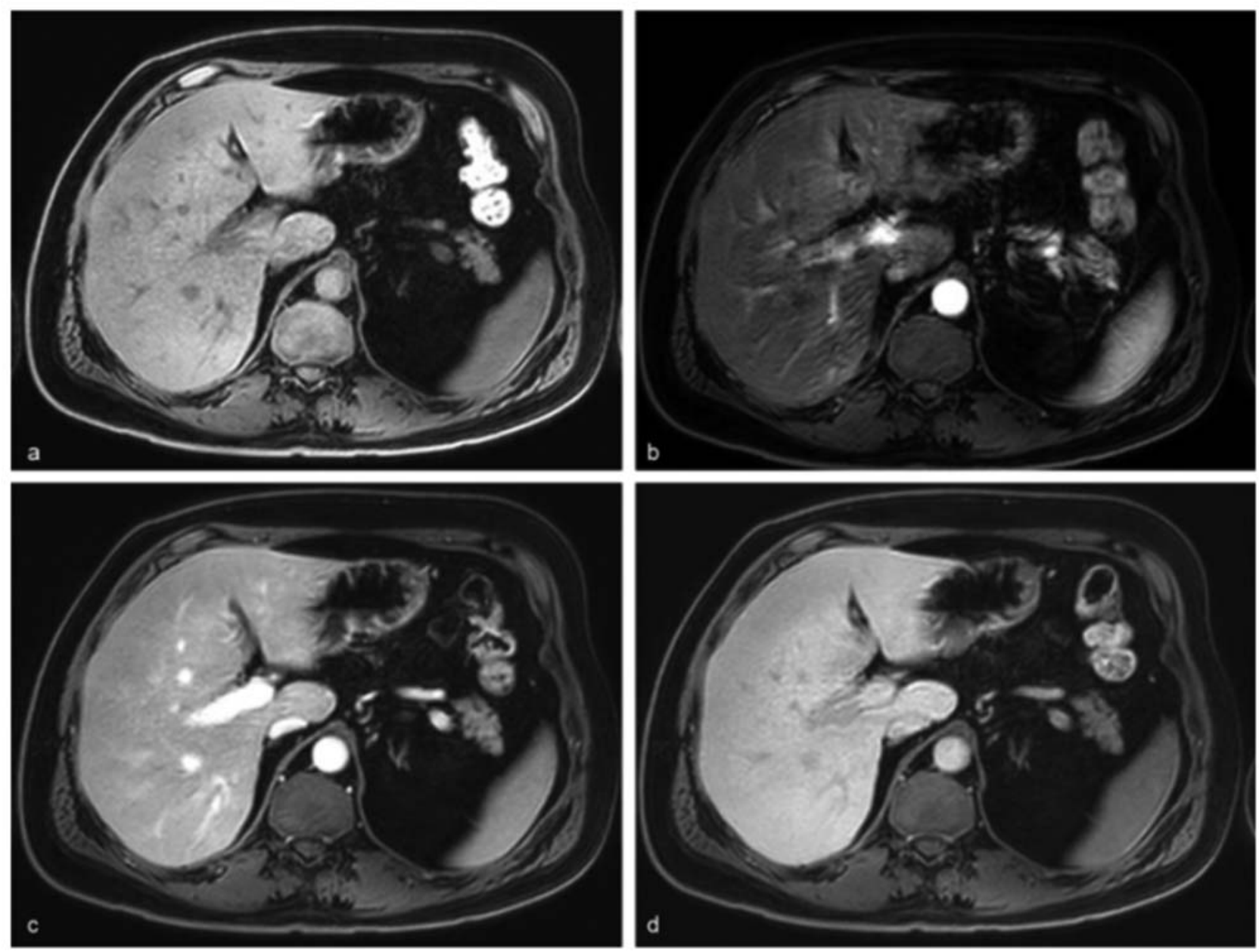

- Fig. 1 Example of imaging artifact related to transient severe respiratory motion (TSM) after injection of gadoxetate disodium in a 49-year-old man with germ cell tumor. Axial fat-saturated T1-weighted images were obtained in a pre-contrast $\mathbf{b}$ arterial $\mathbf{c}$ venous and $\mathbf{d}$ late dynamic phases. Note the sudden onset of motion artifacts in the arterial phase. This patient was suffering from chronic obstructive pulmonary disease, which is discussed as a potential risk factor for TSM.

- Abb. 1 Beispiel eines transienten schweren Atemartefakts (TSA) nach Injektion von Dinatriumgadoxetat bei einem 49 jährigen Patienten mit Keimzelltumor. Axiale fettgesättigte T1 gewichtete Sequenzen a vor Kontrastmittelgabe, sowie in $\mathbf{b}$ arterieller, $\mathbf{c}$ venöser und $\mathbf{d}$ später Kontrastmittelphase. Man beachte die ausschließlich in der arteriellen Kontrastmittelphase auftretenden Bewegungsartefakten. Der Patient litt an chronisch obstruktiver Lungenerkrankung, welche als potentieller Risikofaktor für TSA diskutiert wird.

and potential risk factors according to the inclusion criteria were selected and included for direct comparison of their results $[6,8-15]$. The frequencies of TSM and basic patient characteristics of these nine studies are presented in $>$ Table 1.

\section{Frequency of TSM}

In the first report on TSM in 2013 by Davenport et al., the frequency of severely degraded arterial phase image quality after injection of gadoxetate disodium was described as high as $17 \%$, compared to $2 \%$ after injection of gadobenate disodium [6].

Initially, some radiologists doubted that the appearance of TSM is a reproducible phenomenon [16]. Since 2013, our own and several other groups investigated the frequency of TSM: except for one [17], all studies confirmed consistently that TSM occurs significantly more often after injection of gadoxetate disodium than after injection of gadobenate disodium, or other gadolinium-based contrast agents [6-8, 10, 11, 13, 14].

Interestingly, the results from different investigators show a wide range of frequencies of TSM after injection of gadoxetate disodium. The highest frequency (22\%) was observed by Motosugi et al. in the USA [13]. Hayashi et al. from Japan observed the lowest frequency of TSM (5\%) [11]. As shown in > Table 1, all other studies investigating TSM revealed frequencies over $10 \%$.

In summary, TSM occurs with a frequency of $5-22 \%$ in patients undergoing gadoxetate disodium-enhanced liver MRI. 


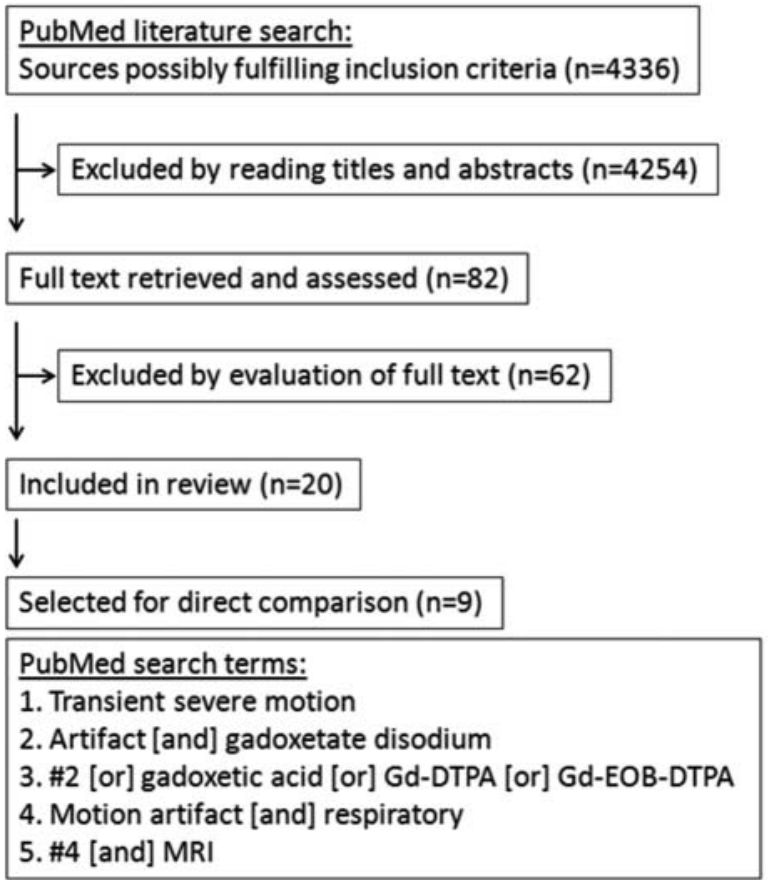

- Fig. 2 Study flow diagram and applied search terms.

- Abb. 2 Diagram des Studienauswahlverfahrens und angewandte Suchbegriffe.

\section{Influence of contrast dose}

One could assume that the dose of gadoxetate disodium influences the occurrence of TSM. This assumption might explain the differences in observed frequencies of TSM. Indeed, the study sites addressing TSM used different doses of gadoxetate disodium: weight-adapted doses of 0.025 or $0.05 \mathrm{mmol} / \mathrm{kg}[11,13]$ fixed doses of $10 \mathrm{ml}$ (package size) or $20 \mathrm{ml}[6,8,10]$ (

Many institutions use the recommended dose of $0.025 \mathrm{mmol} /$ $\mathrm{kg}$ body weight for gadoxetate disodium. This is only a quarter of the dose of conventional extracellular contrast agents $(0.1 \mathrm{mmol} /$ $\mathrm{kg})[18,19]$. The weight-adjusted contrast volume of gadoxetate disodium (concentration: $0.25 \mathrm{~mol}$ ) results in half the volume of other extracellular contrast agents (concentration: $0.5 \mathrm{~mol}$ ) [20]. The smaller volume shortens the duration of arterial enhancement and reduces signal intensity [21]. Therefore, some institutions use higher doses of $0.05 \mathrm{mmol} / \mathrm{kg}[18,22,23]$. Other institutions use a fixed dose of $10 \mathrm{ml}$ equaling the package size, resulting in varying concentrations of gadoxetate disodium, depending on the patient's body weight $[6,8-10,12,14]$.

Davenport et al. demonstrated that gadoxetate disodiumassociated TSM is more frequent (15\%) after application of a fixed dose of $20 \mathrm{ml}$ compared to a fixed dose of $10 \mathrm{ml}$ (10\%) [24]. Other studies, however, were not able to confirm a dose-dependent relationship of gadoxetate disodium and TSM [8, 10, 12]. Also, no correlation between the dose of gadoxetate disodium and the frequency of TSM can be derived when indirectly comparing results from different studies and different sites ( $\triangleright$ Table 2 ). For example, Hayashi et al. found the lowest frequency of TSM (5\%), while our group found one of the highest frequencies (21\%), despite the fact that both groups used the same weight-adjusted dose of $0.025 \mathrm{mmol} / \mathrm{kg}$ [11].

Taken together, a relation between the dose of gadoxetate disodium and the frequency of TSM has been proposed, but only few studies support this hypothesis.

\section{Influence of contrast injection rate}

The injection rate of gadoxetate disodium is another factor potentially influencing the occurrence of TSM. Indeed, the study sites addressing TSM used different injection rates, which may explain the differences in observed frequencies of TSM.

Some institutions administer gadoxetate disodium with a high injection rate of $2 \mathrm{ml} / \mathrm{s}$ to achieve a concentrated bolus for improved arterial phase contrast [6, 8, 9, 12, 13]. Other institutions administer it with a slower injection rate of $1 \mathrm{ml} / \mathrm{s}$ to spread the contrast bolus, thereby reducing the risk of a poorly timed arterial phase [6, 10, 11, 13, 25]. Dilution of gadoxetate disodium with saline is an alternative approach to spread the contrast bolus [9]. Another difference with regard to the injection of contrast agent is the amount of the saline chaser ( $\triangleright$ Table 2 ).

Kim et al. demonstrated that injection of 1:1 diluted gadoxetate disodium significantly reduces overall and severe imaging artifacts in the arterial phase of contrast-enhanced liver MRI [26]. Polanec et al. demonstrated that a slow injection rate of $1 \mathrm{ml} / \mathrm{s}$ in combination with a 1:1 dilution of gadoxetate disodium can significantly reduce the frequency of TSM without a relevant decrease in image quality compared to undiluted injection protocols [27].

Both Hayashi et al. and Motosugi et al. applied the same amount of weight-adapted gadoxetate disodium at a slow rate of $1 \mathrm{ml} / \mathrm{s}$ but observed different frequencies of TSM (5\% vs. $13 \%$ ) $[11,13]$. Studies with faster injection rates of $2 \mathrm{ml} / \mathrm{s}$ also showed varying, but higher frequencies of TSM, ranging from $10 \%$ to $22 \%$ with either weight-adjusted dosing or fixed doses of $10 \mathrm{ml}$ gadoxetate disodium ( $\triangleright$ Table 2$)[6,8,13]$.

Altogether, dilution of the contrast agent and slow injection rates seem to reduce the frequency of TSM, but further studies are needed to confirm this observation.

\section{Influence of arterial phase imaging sequence length}

The length of the imaging sequence is another factor that potentially influences the frequency of observed TSM in the arterial phase of gadoxetate disodium-enhanced liver MRI.

This hypothesis is supported by a recent prospective multicenter placebo-controlled study in healthy volunteers. The study revealed that the maximal breath-hold duration is reduced after gadoxetate disodium administration, which in turn was associated with motion artifacts in the arterial imaging phase [7]. Thus, an imaging sequence that requires a longer breath-hold may more likely be affected by gadoxetate disodium-associated TSM.

Most of the published studies on TSM use three-dimensional, fat-suppressed, T1-weighted spoiled gradient echo sequences for dynamic liver MRI [6, 8-15, 24] ( Table 3). These sequences allow image acquisition during a single breath-hold with adequate 
- Table 1 Frequencies of TSM and basic patient characteristics in selected studies.

- Tab. 1 Häufigkeit der TSA in ausgewählten Studien und wesentliche Charakteristika der eingeschlossenen Patienten.

\begin{tabular}{|c|c|c|c|c|c|c|c|c|c|c|c|c|c|}
\hline \multirow[t]{2}{*}{ author } & \multirow{2}{*}{\multicolumn{2}{|c|}{ Davenport et al. }} & \multirow{2}{*}{$\begin{array}{l}\text { Pietryga } \\
\text { et al. }\end{array}$} & \multirow{2}{*}{$\begin{array}{l}\text { Daven- } \\
\text { port et al. }\end{array}$} & \multirow{2}{*}{\multicolumn{2}{|c|}{ Kim et al. }} & \multirow{2}{*}{\multicolumn{2}{|c|}{ Hayashi et al. }} & \multirow[t]{2}{*}{ Bashir et al. } & \multicolumn{2}{|c|}{ Motosugi et al. } & \multirow[t]{2}{*}{ Shah et al. } & \multirow[t]{2}{*}{ Well et al. } \\
\hline & & & & & & & & & & site $A$ & site B & & \\
\hline $\begin{array}{l}\text { frequency } \\
\text { of TSM }\end{array}$ & \multicolumn{2}{|c|}{$17 / 99$ (17\%) } & $\begin{array}{l}37 / 345 \\
(11 \%)\end{array}$ & $\begin{array}{l}67 / 559 \\
(12 \%)\end{array}$ & \multicolumn{2}{|l|}{$\begin{array}{l}46 / 357 \\
(13 \%)\end{array}$} & \multicolumn{2}{|l|}{$\begin{array}{l}22 / 458 \\
(5 \%)\end{array}$} & $\begin{array}{l}14 / 170^{1} \\
(8 \%)\end{array}$ & $\begin{array}{l}32 / 146 \\
(22 \%)\end{array}$ & $\begin{array}{l}17 / 130 \\
(13 \%)\end{array}$ & $\begin{array}{l}15 / 200 \\
(8 \%)\end{array}$ & $\begin{array}{l}19 / 89 \\
(21 \%)\end{array}$ \\
\hline $\begin{array}{l}\text { publica- } \\
\text { tion date }\end{array}$ & \multicolumn{2}{|l|}{2013} & 2014 & 2014 & \multicolumn{2}{|l|}{2015} & \multicolumn{2}{|l|}{2015} & 2015 & \multicolumn{2}{|l|}{2016} & 2017 & 2017 \\
\hline journal & \multicolumn{2}{|c|}{ Radiology } & Radiology & AJR & \multicolumn{2}{|l|}{ AJR } & \multicolumn{2}{|l|}{ Radiology } & Radiology & Radiology & Radiology & Clin Imaging & RöFo \\
\hline country & \multicolumn{2}{|l|}{ USA } & USA & USA & \multicolumn{2}{|l|}{ USA } & \multicolumn{2}{|l|}{ Japan } & USA & USA & Japan & USA & Germany \\
\hline mean age & 56 male & 58 female & $55 \pm 14$ & $56 \pm 0.55$ & $\begin{array}{l}64 \pm 7 \\
\text { TSM }\end{array}$ & $\begin{array}{l}62 \pm 8 \\
\text { no TSM }\end{array}$ & $\begin{array}{l}61 \pm 1 \\
\text { TSM }\end{array}$ & $\begin{array}{l}63 \pm 2 \\
\text { no TSM }\end{array}$ & $57 \pm 12$ & $52 \pm 15$ & $52 \pm 15$ & $57 \pm 13$ & $55 \pm 15$ \\
\hline mean BMI & 29 & & $28.3 \pm 7$ & $29 \pm 0.3$ & $27 \pm 5$ & $29 \pm 6$ & $24.3 \pm 3.9$ & $23.4 \pm 3.9$ & $29 \pm 7$ & $\mathrm{n} / \mathrm{a}$ & $\mathrm{n} / \mathrm{a}$ & $29 \pm 7$ & $26 \pm 5$ \\
\hline
\end{tabular}

1 occurrence of TSM at initial MR imaging.

- Table 2 Frequency of TSM and contrast injection protocols

- Tab. 2 Häufigkeit der TSA und Kontrastmittel-Injektionsprotokolle.

\begin{tabular}{|c|c|c|c|c|c|c|c|c|c|c|}
\hline \multirow[t]{2}{*}{ author } & \multirow{2}{*}{$\begin{array}{l}\text { Davenport } \\
\text { et al. }\end{array}$} & \multirow{2}{*}{$\begin{array}{l}\text { Pietryga } \\
\text { et al. }\end{array}$} & \multirow{2}{*}{$\begin{array}{l}\text { Davenport } \\
\text { et al. }\end{array}$} & \multirow{2}{*}{$\begin{array}{l}\text { Kim } \\
\text { et al. }\end{array}$} & \multirow{2}{*}{$\begin{array}{l}\text { Hayashi } \\
\text { et al. }\end{array}$} & \multirow{2}{*}{$\begin{array}{l}\text { Bashir } \\
\text { et al. }\end{array}$} & \multicolumn{2}{|c|}{ Motosugi et al. } & \multirow{2}{*}{$\begin{array}{l}\text { Shah et } \\
\text { al. }\end{array}$} & \multirow{2}{*}{$\begin{array}{l}\text { Well } \\
\text { et al. }\end{array}$} \\
\hline & & & & & & & Site A & Site B & & \\
\hline frequency of TSM & $\begin{array}{l}17 / 99 \\
(17 \%)\end{array}$ & $\begin{array}{l}37 / 345 \\
(11 \%)\end{array}$ & $\begin{array}{l}67 / 559 \\
(12 \%)\end{array}$ & $\begin{array}{l}46 / 357 \\
(13 \%)\end{array}$ & $\begin{array}{l}22 / 458 \\
(5 \%)\end{array}$ & $\begin{array}{l}14 / 170 \\
(8 \%)\end{array}$ & $\begin{array}{l}32 / 146 \\
(22 \%)\end{array}$ & $\begin{array}{l}17 / 130 \\
(13 \%)\end{array}$ & $\begin{array}{l}15 / 200 \\
(8 \%)\end{array}$ & $\begin{array}{l}19 / 89 \\
(21 \%)\end{array}$ \\
\hline $\begin{array}{l}\text { concentration of contrast } \\
\text { agent }(\mathrm{mmol} / \mathrm{kg})\end{array}$ & fixed & fixed & fixed & fixed & 0.025 & fixed & 0.05 & 0.025 & fixed & 0.025 \\
\hline $\begin{array}{l}\text { mean volume of contrast } \\
\text { agent }(\mathrm{ml})\end{array}$ & 10 & 10 & $10 / 20$ & 10 & $\mathrm{n} / \mathrm{a}$ & 10 & $\mathrm{n} / \mathrm{a}$ & $\mathrm{n} / \mathrm{a}$ & 10 & 8.1 \\
\hline injection rate (ml/s) & 1 or 2 & 2 & 1 or 2 & 1 & 1 & 2 & 2 & 1 & 2 & 2 \\
\hline saline flush (ml) & $\begin{array}{l}\text { equivalent to } \\
\text { contrast agent }\end{array}$ & 20 & $10 / 20$ & 25 & 40 & 20 & 50 & 20 & $20-30$ & 20 \\
\hline
\end{tabular}


signal-to-noise ratio and spatial resolution [28]. The acquisition times for dynamic liver MRI sequences at the different study sites ranged from 12 to 22 seconds $[8,12,15]$, hence another potential explanation for the difference in observed frequencies of TSM.

It seems conceivable that shorter scan times would decrease the frequency of TSM. Indeed, Luetkens et al. used short acquisition times (i. e., breath-hold times) between 14 and 15 seconds and observed a reduced frequency (6\%) and severity of TSM compared to other studies [17]. However, our group used an equally short imaging protocol (12-15 seconds) but observed one of the highest frequencies of TSM (21\%) [15]. At the same time, Hayashi et al. used a rather long imaging protocol (20s) and observed the overall lowest frequency of TSM (5\%) ( Table 3) [11].

Taken together, a relation between the duration of the arterial phase imaging sequence and frequency of TSM has been proposed, but future prospective studies are needed to confirm this hypothesis.

\section{Potential individual risk factors}

As outlined above, the techniques of contrast application and the length of imaging protocols cannot fully explain the frequency of the occurrence of TSM after the injection of gadoxetate disodium. A different explanation for the occurrence of TSM may therefore be related to specific individual risk factors. Identifying such potential risk factors is essential to develop strategies for avoiding TSM. Several groups investigated the correlation of TSM with potential predisposing risk factors, such as sex, pulmonary disease, body mass index (BMI), previous episodes of TSM, allergies, and other factors ( $\vee$ Table 4) [6 - 13, 24].

With regard to gender, Motosugi et al. showed a predisposition towards male sex [29]. In contrast, Shah et al. proposed a correlation between TSM and female sex [14]. None of the other groups confirmed predisposition of either gender towards TSM [6, 10 12, 14, 15]. ( Table 4)

Concerning pulmonary disease, Davenport et al. revealed that patients with chronic obstructive pulmonary disease have an increased risk of TSM after injection of gadoxetate disodium [9]. Our group confirmed a trend toward significance in patients with pulmonary disease for the occurrence of TSM [15]. Other studies, however, did not replicate this observation $[10,13]$. The results of McClellan et al. indicate that patients with low baseline breathhold duration may be the most affected by gadoxetate disodiumassociated TSM [7]. None of the published studies prospectively assessed the effect of poor breath-hold capability on frequency of TSM. Retrospective analyses of other risk factors, i. e. pleural effusions, ascites, cardiac conditions that are potentially associated with a reduction of breath-hold capability, showed no significant correlation with TSM [10 - 12].

Motosugi et al. found a significantly higher risk of TSM in patients with a high BMI [30]. Hayashi et al. confirmed that body weight contributes to the occurrence of TSM [11]. One has to keep in mind that these results are biased by weight-adapted dosing of gadoxetate disodium, resulting in higher contrast doses in patients with higher BMI. None of the other groups confirmed predisposition of high BMI towards TSM [10].
Bashir et al. found a significantly higher risk of TSM in patients who had experienced TSM before in previous liver MRI examination [12]. Kim et al. found that a known allergy towards iodinated contrast agents may be a possible contributor for TSM. However, this relationship was identified only on univariate analysis and could not be confirmed in a multivariate model [10].

Regarding age, Shah et al. found that the risk of arterial phase motion artifacts increases with age [14], but none of the other groups confirmed a predisposition of higher age towards TSM $[15,24]$.

A large number of other factors, such as pleural effusions, ascites, liver cirrhosis, model of end stage liver disease (MELD) score, and hepatocellular carcinoma have been investigated as potential risk factors of TSM $[8,9,12]$. However, none of these potential risk factors showed a significant correlation with the occurrence of TSM.

In summary, several potential predisposing individual risk factors for the appearance of TSM have been described, but results are inconsistent. Conceivably, pulmonary disease may represent a potential risk factor for TSM, but future prospective studies are needed to confirm this hypothesis.

\section{Effects of gadoxetic disodium injection on physio- logical parameters}

As outlined above, no clear predisposing individual risk factor for the occurrence of TSM has been identified. Understanding the mechanism of TSM is therefore another essential strategy to avoid TSM. As a first step, several investigators assessed the effects of gadoxetic disodium injection on physiological parameters. It should be noted that breath-hold failure after injection of gadoxetate disodium is a self-terminating effect with a duration of less than $60-90$ seconds. After this interval, the acquisition of the portal venous phase begins and is not affected by motion artifacts.

Several studies were able to show that injection of gadoxetate disodium leads to an increased rate of breath-hold failures that are associated with TSM [13, 30]. Moreover, McClellan et al. revealed that the maximal breath-hold duration is significantly reduced in healthy volunteers after gadoxetate disodium administration. The reduction in maximal achievable breath-hold duration was associated with TSM [7].

With regard to subjective dyspnea, several studies observed that subjective self-reported dyspnea occurs significantly more frequently with gadoxetate disodium than with gadobenate dimeglumine [6, 13, 31]. Interestingly, self-reported dyspnea shows no correlation with the occurrence of TSM [13]. In contrast to the above-mentioned studies, Hayashi et al. did not detect an increase in self-reported dyspnea after injection of gadoxetate disodium [11].

None of the studies revealed a significant decrease in blood oxygen saturation during the arterial phase. Also, no significant correlation was identified between changes in blood oxygen saturation and the occurrence of TSM [7, 11, 13, 30], neither did any of the studies reveal a significant change in heart rate after injection of gadoxetate disodium [7, 11, 13]. 
- Table 3 Frequency of TSM and MR sequence acquisition protocols

- Tab. 3 Häufigkeit der TSA und MR-Sequenzprotokolle.

\begin{tabular}{|c|c|c|c|c|c|c|c|c|c|c|}
\hline \multirow[t]{2}{*}{ author } & \multirow[t]{2}{*}{ Davenport et al. } & \multirow[t]{2}{*}{ Pietryga et al. } & \multirow[t]{2}{*}{ Davenport et al. } & \multirow[t]{2}{*}{ Kim et al. } & \multirow[t]{2}{*}{ Hayashi et al. } & \multirow[t]{2}{*}{ Bashir et al. } & \multicolumn{2}{|c|}{ Motosugi et al. } & \multirow[t]{2}{*}{ Shah et al. } & \multirow[t]{2}{*}{ Well et al. } \\
\hline & & & & & & & Site A & Site B & & \\
\hline frequency of TSM & $\begin{array}{l}17 / 99 \\
(17 \%)\end{array}$ & $\begin{array}{l}37 / 345 \\
(11 \%)\end{array}$ & $\begin{array}{l}67 / 559 \\
(12 \%)\end{array}$ & $\begin{array}{l}46 / 357 \\
(13 \%)\end{array}$ & $\begin{array}{l}22 / 458 \\
(5 \%)\end{array}$ & $14 / 170(8 \%)$ & $\begin{array}{l}32 / 146 \\
(22 \%)\end{array}$ & $\begin{array}{l}17 / 130 \\
(13 \%)\end{array}$ & $\begin{array}{l}15 / 200 \\
(8 \%)\end{array}$ & $\begin{array}{l}19 / 89 \\
(21 \%)\end{array}$ \\
\hline imaging sequence & $3 \mathrm{D}$ spoiled GRE & $\mathrm{VIBE}^{1}$ & 3D spoiled GRE & GRAPPA $^{2}$ & GRAPPA $^{2}$ & 3D spoiled GRE & LAVA $^{3}$ & LAVA $^{3}$ & $\begin{array}{l}\text { LAVA }^{3} / \\
\text { THRIVE } / \\
\text { mDixon }^{5}\end{array}$ & $\begin{array}{l}\text { eTHRIVE }^{4} / \\
\text { mDixon }^{5}\end{array}$ \\
\hline TR & 3.6 & $3.7-4.4$ & $3.6 / 3.7-4.4$ & $\begin{array}{l}3.8 \\
4.3\end{array}$ & 3.98 & $3.7-4.4$ & $3.7-4.1$ & $3.4-4.7$ & $\begin{array}{l}4.2-4.5 \\
3.0-4.23 .4\end{array}$ & $\begin{array}{l}3.9 \\
3.5\end{array}$ \\
\hline TE & 1.3 & $1.3-2.1$ & $\begin{array}{l}1.3 \\
1.3-2.1\end{array}$ & $\begin{array}{l}1.7 \\
1.9\end{array}$ & 1.5 & $1.3-2.1$ & $1.7-1.9$ & $1.4-2.1$ & $\begin{array}{l}1.7-2.1 \\
1.4-2.11 .7\end{array}$ & $1.81 .2 / 2.3$ \\
\hline FA & 12 & $9-12$ & $\begin{array}{l}12 \\
9-12\end{array}$ & $\begin{array}{l}12 \\
9\end{array}$ & 12 & $9-12$ & $12-15$ & $12-15$ & $\begin{array}{l}12 \\
10-70 \\
15-32\end{array}$ & 10 \\
\hline $\mathrm{FOV}(\mathrm{mm})$ & entire liver & $256 \times 156-192$ & entire liver & $370 \times 300$ & entire liver & $256 \times 156-192$ & $360 \times 380$ & $340 \times 380$ & entire liver & $\begin{array}{l}330 \times 330 / \\
400 \times 400\end{array}$ \\
\hline section thickness (mm) & 4 & 4 & 4 & 3 & - & 4 & $5 / 3.4$ & $5 / 4$ & $3-7$ & $4.4 / 1.7$ \\
\hline $\begin{array}{l}\text { arterial phase } \\
\text { acquisition time (s) }\end{array}$ & $18-22$ & 23 & $18-22$ & 16 & 20 & 23 & $22 / 20$ & 16 & $\mathrm{n} / \mathrm{a}$ & $12-15$ \\
\hline triggering method & $\begin{array}{l}\text { manual fluoro- } \\
\text { scopic/automated } \\
\text { bolus tracking }\end{array}$ & fixed delay & $\begin{array}{l}\text { manual fluoro- } \\
\text { scopic/automated- } \\
\text { bolus tracking }\end{array}$ & $\begin{array}{l}\text { manual } \\
\text { fluoroscopic } \\
\text { trigger }\end{array}$ & $\begin{array}{l}\text { manual fluoro- } \\
\text { scopic trigger }\end{array}$ & $\begin{array}{l}\text { fixed delay/ } \\
\text { fluoroscopic } \\
\text { trigger/auto- } \\
\text { mated bolus } \\
\text { tracking }\end{array}$ & $\mathrm{n} / \mathrm{a}$ & $\mathrm{n} / \mathrm{a}$ & $\begin{array}{l}\text { fixed delay/ } \\
\text { fluoroscopic } \\
\text { trigger }\end{array}$ & fixed delay \\
\hline $\begin{array}{l}1 \text { VIBE = volume interpolat } \\
2 \text { GRAPPA = Generalized } \\
{ }^{3} \text { LAVA = spectrally selecti } \\
{ }^{4} \text { eTHRIVE = Enhanced } \mathrm{T} 1 \\
5 \text { mDixon = multi-echo Dix }\end{array}$ & $\begin{array}{l}\text { breath-hold examina } \\
\text { calibrating partially } \\
\text { ntermittent fat inver } \\
\text { h Resolution Isotrop }\end{array}$ & $\begin{array}{l}\text { n. } \\
\text { Allel acquisition. } \\
\text { olume Excitation. }\end{array}$ & & & & & & & & \\
\hline
\end{tabular}


- Table 4 Frequency of TSM and potential risk factors

- Tab.4 Häufigkeit der TSA und potentielle ursächliche Risikofaktoren.

\begin{tabular}{|c|c|c|c|c|c|c|c|c|c|c|}
\hline \multirow[t]{2}{*}{ author } & \multirow{2}{*}{$\begin{array}{l}\text { Davenport } \\
\text { et al. }\end{array}$} & \multirow{2}{*}{$\begin{array}{l}\text { Pietryga } \\
\text { et al. }\end{array}$} & \multirow{2}{*}{$\begin{array}{l}\text { Davenport } \\
\text { et al. }\end{array}$} & \multirow[t]{2}{*}{ Kim et al. } & \multirow{2}{*}{$\begin{array}{l}\text { Hayashi } \\
\text { et al. }\end{array}$} & \multirow{2}{*}{$\begin{array}{l}\text { Bashir } \\
\text { et al. }\end{array}$} & \multicolumn{2}{|c|}{ Motosugi et al. } & \multirow{2}{*}{$\begin{array}{l}\text { Shah } \\
\text { et al. }\end{array}$} & \multirow{2}{*}{$\begin{array}{l}\text { Well } \\
\text { et al. }\end{array}$} \\
\hline & & & & & & & Site $A$ & Site B & & \\
\hline frequency of TSM & $\begin{array}{l}17 / 99 \\
(17 \%)\end{array}$ & $\begin{array}{l}37 / 345 \\
(11 \%)\end{array}$ & $\begin{array}{l}67 / 559 \\
(12 \%)\end{array}$ & $\begin{array}{l}46 / 357 \\
(13 \%)\end{array}$ & $\begin{array}{l}22 / 458 \\
(5 \%)\end{array}$ & $\begin{array}{l}14 / 170 \\
(8 \%)\end{array}$ & $\begin{array}{l}32 / 146 \\
(22 \%)\end{array}$ & $\begin{array}{l}17 / 130 \\
(13 \%)\end{array}$ & $\begin{array}{l}15 / 200 \\
(8 \%)\end{array}$ & $\begin{array}{l}19 / 89 \\
(21 \%)\end{array}$ \\
\hline age & n.s. & n.s. & n.s. & n.s. & n.s. & n.s. & n.s. & n.s. & old age $\mathrm{e}^{1,2}$ & n.s. \\
\hline sex & n.s. & n.s. & n.s. & n.s. & n.s. & n.s. & male $^{2}$ & male $^{2}$ & female ${ }^{1,2}$ & n.s. \\
\hline BMI & n.s. & n.s. & n.s. & n.s. & high $\mathrm{BMI}^{2}$ & n.s. & $\begin{array}{l}\text { high } \\
\mathrm{BMI}^{2}\end{array}$ & $\begin{array}{l}\text { high } \\
\mathrm{BMI}^{2}\end{array}$ & n.s. & n.s. \\
\hline ascites & n.s. & n.s. & n.s. & n.s. & n.s. & n.s. & n.s. & n.s. & n.s. & n.s. \\
\hline pleural effusion & n.s. & n.s. & n.s. & n.s. & n.s. & n.s. & n.s. & n.s. & n.s. & n.s. \\
\hline lung disease & n.s. & n.s. & $\mathrm{COPD}^{3}$ & n.s. & n.s. & n.s. & n.s. & n.s. & - & n.s. \\
\hline previous exposure & - & - & - & n.s. & $\begin{array}{l}\text { gadolinium } \\
\text { exposure }^{4}\end{array}$ & n.s. & - & - & - & n.s. \\
\hline previous TSM & - & - & - & $\begin{array}{l}\text { previous } \\
\text { TSM }^{2,5}\end{array}$ & n.s. & $\begin{array}{l}\text { previous } \\
\text { TSM }^{3}\end{array}$ & - & - & - & - \\
\hline allergies & n.s. & - & n.s. & $\begin{array}{l}\text { iodinated } \\
\text { contrast }{ }^{4,5}\end{array}$ & n.s. & - & n.s. & n.s. & - & n.s. \\
\hline chronic liver disease & n.s. & n.s. & n.s. & n.s. & n.s. & n.s. & n.s. & n.s. & - & n.s. \\
\hline hepatocellular carcinoma & n.s. & - & - & n.s. & - & - & - & - & - & n.s. \\
\hline hypertonus & - & - & - & n.s. & - & - & n.s. & n.s. & - & n.s. \\
\hline volume of contrast agent & n.s. & n.s. & $20 \mathrm{ml}^{4}$ & n.s. & n.s. & n.s. & n.s. & n.s. & n.s. & n.s. \\
\hline injection rate & n.s. & n.s. & n.s. & n.s. & n.s. & n.s. & n.s. & n.s. & n.s. & n.s. \\
\hline $\begin{array}{l}\text { n.s. not significant. } \\
1 \text { associated with respiratc } \\
2 \mathrm{p} \leq 0.05 \text {. } \\
3 \mathrm{p} \leq 0.0001 . \\
4 \mathrm{p} \leq 0.01 \text {. } \\
5 \text { statistically significant or }\end{array}$ & tion artifacts. & & & & & & & & & \\
\hline
\end{tabular}


Taken together, impairment of breath-hold ability after injection of gadoxetate disodium is a reproducible result that has been confirmed by several studies. In addition to that, the impaired breath-hold ability is associated with TSM. However, the underlying reason for breath-hold failure and consecutive TSM remains unclear.

\section{Strategies to avoid TSM-associated arterial phase image degradation}

As outlined above, breath-hold failure after injection of gadoxetate disodium has been identified as the cause for TSM. As long as the underlying mechanism for the breath-hold failure is not identified, TSM cannot be avoided in the arterial phase of liver MRI. Therefore, technical strategies to avoid or mitigate the effects of TSM on the arterial phase image quality need to be identified. Several investigators explored the possibilities of modified imaging protocols to reduce the impact of TSM on image degradation [8, 32, 33].

Pietryga et al. assessed fast, multi-arterial phase imaging in a single breath-hold (23 seconds) that provides three arterial phase image sets with reduced or absent motion artifacts [8]. With this approach, Pietryga et al. were able to recover up to $80 \%$ of arterial phases that would otherwise have been degraded in a standard imaging setting. However, the technique results in a reduced signal-to-noise ratio and/or spatial resolution. Recently, Rahimi et al. proposed a time-resolved interleaved variable density (IVD) MR sequence for arterial phase imaging of the liver [34]. The IVD technique provides five arterial phase image sets with both high spatial and temporal resolution and warrants further evaluation in this setting.

The effects of motion can also be reduced by using inherently motion-resistant MR imaging techniques, such as radial or spiral k-space filling trajectories [35, 36]. Another promising approach for improved arterial phase images is the utilization of freebreathing techniques, which allow contrast-enhanced dynamic liver examinations without the need for breath-holds [32]. Kaltenbach et al. demonstrated that free breathing sequences do not impair image quality and can mitigate the effect of TSM [33].

An additional aspect that has to be considered is the proper preparation and training of patients by the responsible technician. Gutzeit et al. were able to show that use of an extended breathing command previous to and during the injection of gadoxetate disodium significantly reduced the amount of breathing artifacts compared to examinations with standard breathing commands [37, 38]. A combination of both, motion-resistant imaging sequences and modified breathing commands can further reduce the number of compromised arterial phases [39].

In summary, short acquisition times, multi-arterial phase imaging, alternative k-space filling trajectories, free-breathing techniques, and breath-hold training warrant further prospective studies to assess their potential in reducing TSM-associated arterial phase image degradation.

\section{Directions of future research}

Based on the results presented above, we can assume that gadoxetate disodium injection impairs the breath-hold ability, which in turn is associated with the occurrence of $\operatorname{TSM}[7,13]$. The underlying mechanism for the impaired breath-hold ability has not been identified. Several associated risk factors for TSM have been described, such as high dose of gadoxetate disodium, previous episodes of TSM, high BMI, and pulmonary disease [6, 9, 11, 13, 14]. However, results are inconsistent, and no unanimously validated risk factor could be identified. Therefore, future studies are needed to improve the understanding of this phenomenon as well as the diagnostic and clinical impact of TSM.

First, it is important to elucidate the underlying reason for the breath-hold failure after injection of gadoxetate disodium. More research is needed regarding the effects of gadoxetate disodium injection on cardiac and pulmonary function. This includes determination of the exact time point of the onset of breath-hold failure after injection of gadoxetate disodium, e. g. by fluoroscopic imaging of the lung during contrast injection or continuous image acquisition during MRI examinations. The results might explain the exact mechanism that triggers breath-hold failure and consecutive TSM.

Second, future studies also need to further investigate the previously assessed and other, currently unknown, potential risk factors for TSM. Knowing such risk factors may help to identify patients that should not undergo gadoxetate disodium-based, but instead extracellular gadolinium-based contrast-enhanced liver MRI protocols.

Third, it is important to assess if and how TSM hampers the diagnostic accuracy of the entire liver MRI examination [15]. Arterial enhancement is a cardinal imaging feature for diagnosis of HCC and other arterially enhancing lesions [19]. Nevertheless, some of these lesions have other specific imaging features that are displayed in other sequences of a comprehensive liver MRI examination, thereby potentially providing a confident diagnosis despite TSA in the arterial imaging phase.

A thorough assessment of a diagnosis-limiting effect of TSM requires a prospective study that ideally fulfills two major prerequisites: first, an intra-patient comparison is required, with both, an extracellular gadolinium-based contrast agent and gadoxetate disodium. Only this direct comparison will allow assessment of whether arterially enhancing lesions (i. e. HCC) are detected with the extracellular contrast agent and if these lesions are then missed or equally well detected with gadoxetate disodium in cases of TSM. Second, all identified lesions require histopathological confirmation or another robust reference standard for validation.

Since only $5-22 \%$ of all patients experience TSM, large prospective studies are required to answer the question of whether the overall diagnostic accuracy of gadoxetate disodium-enhanced liver MRI is significantly hampered by TSM. Also, the patient collective that may potentially be affected has to be clearly defined. Diagnostic accuracy in patients with hypervascular lesions such as HCC, FNH, adenomas and hypervascular metastases (renal carcinomas, neuroendocrine tumors) may be more affected, since arterial enhancement is a cardinal imaging feature of these lesions, which might be hampered by TSM. Diagnostic accuracy in patients with suspected colorectal liver metastases may not be affected at all, since most sensitive detection of liver metastases relies on the hepatobiliary phase of gadoxetate disodium, which is not affected by TSM [4, 19]. 


\section{Summary}

Suboptimal or non-diagnostic image quality due to motion artifacts in the arterial phase of gadoxetate disodium-enhanced liver MRI has been termed transient severe motion (TSM). TSM occurs in $5-22 \%$ of patients undergoing gadoxetate disodium-enhanced liver MRI. TSM is caused by impaired breath-hold ability after gadoxetate disodium injection. The dose of applied contrast agent, repeated exposure to gadoxetate disodium, high BMI and pulmonary disease have been described as potential risk factors for TSM. However, there are only a few concordant results on this topic and the underlying pathophysiology for impaired breath-hold ability and occurrence of TSM has not been identified. Proposed strategies for the prevention of TSM are slow injection rates and low doses of diluted gadoxetate disodium. Thorough patient preparation and breath-hold training can further reduce the frequency of TSM. Accelerated and free-breathing MRI sequence protocols may minimize the effects of TSM. Further prospective studies are needed to confirm these strategies and to identify the underlying mechanism of TSM.

\section{Conflict of Interest}

The authors declare that they have no conflict of interest.

\section{Acknowledgement}

We thank Ingrid Krause for her advice and critical reading of the manuscript.

\section{References}

[1] Bashir MR, Gupta RT, Davenport MS et al. Hepatocellular carcinoma in a North American population: does hepatobiliary MR imaging with Gd-EOB-DTPA improve sensitivity and confidence for diagnosis? J Magn Reson Imaging 2013; 37: 398-406

[2] Zech C], Herrmann KA, Reiser MF et al. MR imaging in patients with suspected liver metastases: value of liver-specific contrast agent Gd-EOB-DTPA. Magn Reson Med Sci 2007; 6: 43-52

[3] Di Martino M, Marin D, Guerrisi A et al. Intraindividual comparison of gadoxetate disodium-enhanced MR imaging and 64-section multidetector $\mathrm{CT}$ in the Detection of hepatocellular carcinoma in patients with cirrhosis. Radiology 2010; 256: 806-816

[4] Muhi A, Ichikawa T, Motosugi U et al. Diagnosis of colorectal hepatic metastases: comparison of contrast-enhanced $\mathrm{CT}$, contrast-enhanced US, superparamagnetic iron oxide-enhanced MRI, and gadoxetic acidenhanced MRI. J Magn Reson Imaging 2011; 34: 326- 335

[5] Tanimoto A, Kuwatsuru R, Kadoya M et al. Evaluation of gadobenate dimeglumine in hepatocellular carcinoma: results from phase II and phase III clinical trials in Japan. J Magn Reson Imaging 1999; 10: 450 - 460

[6] Davenport MS, Viglianti BL, Al-Hawary MM et al. Comparison of Acute Transient Dyspnea after Intravenous Administration of Gadoxetate Disodium and Gadobenate Dimeglumine: Effect on Arterial Phase Image Quality. Radiology 2013; 266: $452-461$

[7] McClellan TR, Motosugi U, Middleton MS et al. Intravenous Gadoxetate Disodium Administration Reduces Breath-holding Capacity in the Hepatic Arterial Phase: A Multi-Center Randomized Placebo-controlled Trial. Radiology 2017; 282: 361-381
[8] Pietryga JA, Burke LMB, Marin D et al. Respiratory Motion Artifact Affecting Hepatic Arterial Phase Imaging with Gadoxetate Disodium: Examination Recovery with a Multiple Arterial Phase Acquisition. Radiology 2014; 271: 426-434

[9] Davenport MS, Bashir MR, Pietryga JA et al. Dose-Toxicity Relationship of Gadoxetate Disodium and Transient Severe Respiratory Motion Artifact. Am J Roentgenol 2014; 203: 796-802

[10] Kim SY, Park SH, Wu EH et al. Transient Respiratory Motion Artifact During Arterial Phase MRI With Gadoxetate Disodium: Risk Factor Analyses. Am J Roentgenol 2015; 204: 1220 - 1227

[11] Hayashi T, Saitoh S, Tsuji Y et al. Influence of Gadoxetate Disodium on Oxygen Saturation and Heart Rate during Dynamic Contrast-enhanced MR Imaging. Radiology 2015; 276: 756 - 765

[12] Bashir MR, Castelli P, Davenport MS et al. Respiratory Motion Artifact Affecting Hepatic Arterial Phase MR Imaging with Gadoxetate Disodium Is More Common in Patients with a Prior Episode of Arterial Phase Motion Associated with Gadoxetate Disodium. Radiology 2015; 274: $141-148$

[13] Motosugi U, Bannas P, Bookwalter CA et al. An Investigation of Transient Severe Motion Related to Gadoxetic Acid-enhanced MR Imaging. Radiology 2016; 279: 93 - 102

[14] Shah MR, Flusberg M, Paroder V et al. Transient arterial phase respiratory motion-related artifact in MR imaging of the liver: an analysis of four different gadolinium-based contrast agents. Clin Imaging 2017; 41: 23 27

[15] Well L, Rausch VH, Adam G et al. Transient Severe Motion Artifact Related to Gadoxetate Disodium-Enhanced Liver MRI: Frequency and Risk Evaluation at a German Institution. Rofo 2017; [Epub ahead of print]

[16] Motosugi U. Gadoxetic acid-induced acute transient dyspnea: the perspective of Japanese radiologists. Magn Reson Med Sci MRMS an Off J Japan Soc Magn Reson Med 2015; 14: 163 -164

[17] Luetkens JA, Kupczyk PA, Doerner ] et al. Respiratory motion artefacts in dynamic liver MRI: a comparison using gadoxetate disodium and gadobutrol. Eur Radiol 2015; 25: 3207 - 3213

[18] Tamada T, Ito K, Sone T et al. Dynamic contrast-enhanced magnetic resonance imaging of abdominal solid organ and major vessel: comparison of enhancement effect between Gd-EOB-DTPA and Gd-DTPA. J Magn Reson Imaging 2009; 29: 636-640

[19] Weinrich JM, Well L, Bannas P. Optimized detection and characterization of liver metastases. Radiologe 2017; 57: 373 - 381

[20] Reimer P, Vosshenrich R. Kontrastmittel in der Radiologie. Radiologe 2013; 53: $153-164$

[21] Bae KT. Peak contrast enhancement in CT and MR angiography: when does it occur and why? Pharmacokinetic study in a porcine model. Radiology 2003; 227: 809-816

[22] Brismar TB, Dahlstrom N, Edsborg N et al. Liver vessel enhancement by Gd-BOPTA and Gd-EOB-DTPA: a comparison in healthy volunteers. Acta Radiol 2009; 50: 709-715

[23] Ringe KI, Husarik DB, Sirlin CB et al. Gadoxetate disodium-enhanced MR of the liver: part 1, protocol optimization and lesion appearance in the noncirrhotic liver. Am J Roentgenol 2010; 195: 13-28

[24] Davenport MS, Caoili EM, Kaza RK et al. Matched within-Patient Cohort Study of Transient Arterial Phase Respiratory Motion-related Artifact in MR Imaging of the Liver: Gadoxetate Disodium versus Gadobenate Dimeglumine. Radiology 2014; 272: 123-131

[25] Zech C], Vos B, Nordell A et al. Vascular enhancement in early dynamic liver MR imaging in an animal model: comparison of two injection regimen and two different doses Gd-EOB-DTPA (gadoxetic acid) with standard Gd-DTPA. Invest Radiol 2009; 44: 305-310

[26] Kim YK, Lin WC, Sung K et al. Reducing Artifacts during Arterial Phase of Gadoxetate Disodium-enhanced MR Imaging: Dilution Method versus Reduced Injection Rate. Radiology 2017; 283: 429-437 
[27] Polanec SH, Bickel H, Baltzer PAT et al. Respiratory motion artifacts during arterial phase imaging with gadoxetic acid: Can the injection protocol minimize this drawback? J Magn Reson Imaging 2017; 46: $1107-1114$

[28] Guglielmo FF, Mitchell DG, Gupta S. Gadolinium contrast agent selection and optimal use for body MR imaging. Radiol Clin North Am 2014; 52 : $637-656$

[29] Motosugi U, Bannas P, Hernando D et al. Intraindividual Crossover Comparison of Gadoxetic Acid Dose for Liver MRI in Normal Volunteers. Magn Reson Med Sci 2016; 15: 60-72

[30] Park YS, Lee CH, Yoo JL et al. Hepatic Arterial Phase in Gadoxetic AcidEnhanced Liver Magnetic Resonance Imaging: Analysis of Respiratory Patterns and Their Effect on Image Quality. Invest Radiol 2016; 51 $127-133$

[31] Davenport MS, Malyarenko DI, Pang Y et al. Effect of Gadoxetate Disodium on Arterial Phase Respiratory Waveforms Using a Quantitative Fast Fourier Transformation-Based Analysis. Am J Roentgenol 2017; 208: $328-336$

[32] Kim KW, Lee JM, Jeon YS et al. Free-breathing dynamic contrast-enhanced MRI of the abdomen and chest using a radial gradient echo sequence with $\mathrm{K}$-space weighted image contrast (KWIC). Eur Radiol 2013; 23: $1352-1360$

[33] Kaltenbach B, Roman A, Polkowski C et al. Free-breathing dynamic liver examination using a radial 3D T1-weighted gradient echo sequence with moderate undersampling for patients with limited breath-holding capacity. Eur J Radiol 2017; 86: 26-32
[34] Salmani Rahimi M, Korosec FR, Wang K et al. Combined dynamic contrast-enhanced liver MRI and MRA using interleaved variable density sampling. Magn Reson Med 2015; 73: 973-983

[35] McKenzie CA, Lim D, Ransil BJ et al. Shortening MR image acquisition time for volumetric interpolated breath-hold examination with a recently developed parallel imaging reconstruction technique: clinical feasibility. Radiology 2004; 230: 589-594

[36] Vogt FM, Antoch G, Hunold P et al. Parallel acquisition techniques for accelerated volumetric interpolated breath-hold examination magnetic resonance imaging of the upper abdomen: assessment of image quality and lesion conspicuity. J Magn Reson Imaging 2005; 21: 376 - 382

[37] Gutzeit A, Matoori S, Froehlich J et al. Reduction in Respiratory Motion Artifacts on Gadoxetate Acid-enhanced MR Images after Training Technicians. Radiology 2016; 279: 981 - 982

[38] Gutzeit A, Matoori S, Froehlich JM et al. Reduction in respiratory motion artefacts on gadoxetate-enhanced MRI after training technicians to apply a simple and more patient-adapted breathing command. Eur Radiol 2016; 26: 2714-2722

[39] Fahlenkamp UL, Wagner M, Nickel D et al. Novel Dynamic Hepatic Magnetic Resonance Imaging Strategy Using Advanced Parallel Acquisition, Rhythmic Breath-Hold Technique, and Gadoxetate Disodium Enhancement. Invest Radiol 2016; 51: 33-40 